\title{
Research Paper \\ Prediction of Educational Motivation Based on Mental Toughness and Capacity of Sustaining Effort and Interest for Long-Term Purposes
}

\author{
Farzin Bagheri Sheykhangafshe ${ }^{1}$, Reza Shabahang ${ }^{2}$, Akram Sadat Abbasi ${ }^{2}$, Seyedeh Maryam Mousavi ${ }^{* 3}$, \\ Vahid Hajialiani ${ }^{2}$, Marzieh Shahryari Sarhadi ${ }^{4}$ \\ 1. M.A. in General Psychology, Faculty of Literature and Humanity Sciences, University of Guilan, Rasht, Iran \\ 2. M.A. in General Psychology, Faculty of Psychology and Educational Sciences, University of Tehran, Iran \\ 3. Ph.D. in Health Psychology, Department of Nursing, Rasht Branch, Islamic Azad University, Rasht, Iran \\ 4. M.A. in Clinical Psychology, Faculty of Literature and Human Sciences, Shahid Bahonar University of Kerman, Iran
}

Citation: Bagheri Sheykhangafshe F, Shabahang R, Abbasi AS, Mousavi SM, Hajialiani V, Shahryari Sarhadi M. Prediction of educational motivation based on mental toughness and capacity of sustaining effort and interest for long-term purposes. Quarterly Journal of Child Mental Health. 2020; 6(4): 13-22.

http://dx.doi.org/10.29252/jcmh.6.4.3

\section{A R T I C L E I N F O}

\section{Keywords:}

Educational motivation, mental toughness, grit, student

Received: 9 Jun 2019

Accepted: 7 Dec 2019 Available: 22 Feb 2020

\section{A B S T R A C T}

Background and Purpose: Motivational processes underlie students' learning behaviors that can be influenced by various psychological factors. One of these variables is called mental toughness which different levels of it can affect students' academic performance. On the other hand, the capacity to sustain effort and interest for long-term goals is an effective factor related to academic success. In this regard, the present study aimed to investigate the role of psychological strength and the capacity to maintain effort and interest for long-term goals (stability) in predicting students' academic achievement.

Method: This study is descriptive and correlational. The statistical population of the study consisted of all high school students in the first district of Rasht city in the academic year of 2018-19. The sample included 300 students from this papulation (150 female students and 150 male students) who were selected using convenience sampling method. Data were collected using the Educational Motivation Scale (Harter, 1981), Mental Toughness Questionnaire (Sheard, Golby, \& Van Wersch, 2009), and Short Grit Scale (Duckworth \& Quinn, 2009). Data were analyzed by SPSS software using Pearson correlation and multiple regression.

Results: The results of multiple regression analysis showed that the effect of confidence $(0.17)$, constancy (0.23), control (0.21) and grit (0.18) on students' academic motivation was positive and significant. Also, mental toughness and the capacity of sustaining effort and interest for long-term purposes (grit) significantly predict students' academic motivation $(\mathrm{p}<0.01)$. The results also showed that mental toughness, capacity of sustaining effort, and interest for long-term goals (grit) predict $17 \%$ of students' academic motivation.

Conclusion: According to the research findings, it was found that students who have long-term goals and have a clear plan for their academic future have a higher academic motivation. Also, students who achieve high scores in mental toughness show greater consistency and stability in their studies and will continue to study with a more sustainable motivation. It is therefore essential for teachers and families to focus more on these topics to strengthen students' mental toughness and grit.

\footnotetext{
* Corresponding author: Seyedeh Maryam Mousavi, Ph.D. in Health Psychology, Department of Nursing, Rasht Branch, Islamic Azad University, Rasht, Iran.

E-mail addresses: Mmousavi.msc@gmail.com
} 


\section{ييش بينى انكيزش تحصيلى بر اساس استحكام روانى و ظرفيت نكهدارى تلاش و علاقه براى اهداف بلندمدت}

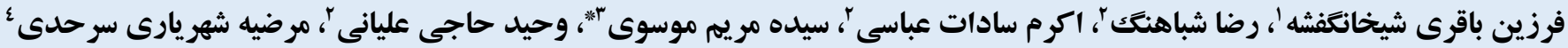

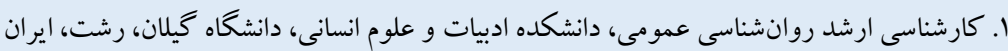

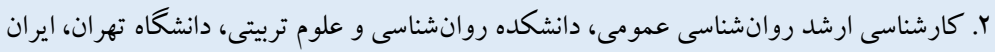

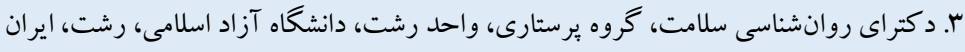

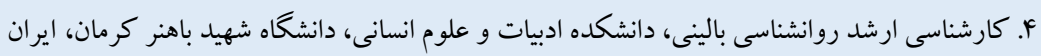

\section{جكيده}

زمينه و هدف: فرايندهاى انخيزشى زيربناى رفتارهاى يادگيرى دانش آموزان هستد كه مىتواند تحت تأثير عوامل روانشناختى گوناگون قرار گيرد. از جمله اين متغيرها، استحكام روانى نام دارد كه سطوح متفاوت آن مى تواند بر عملكرد تحصيلى دانش آموزان تأثير كذار باشد.

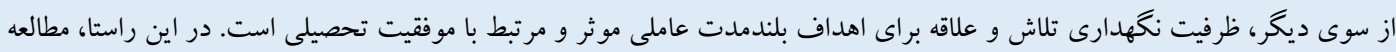

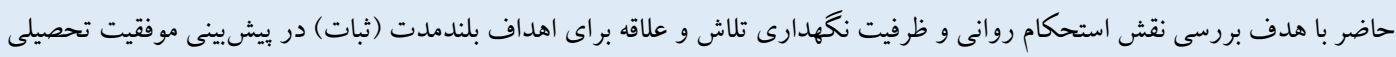
دانش آموزان انجام شد. روش: مطالعه حاضر توصيفى و از نوع همبستخى است. جامعه آمارى بثوهش شامل تمامى دانش آموزان مدارس متوسطه اول ناحيه يكك شهر رشت در نيمسال تحصيلى لو

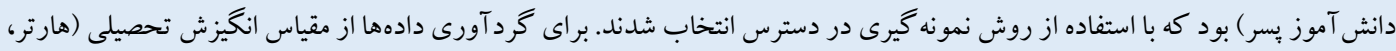

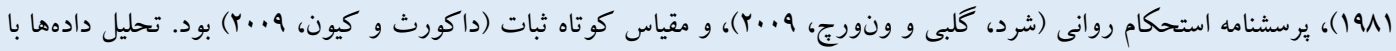

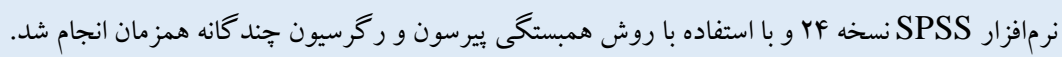

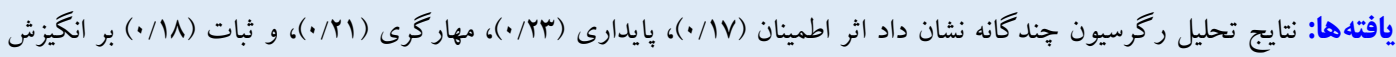

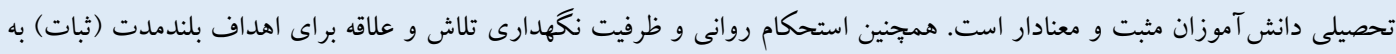

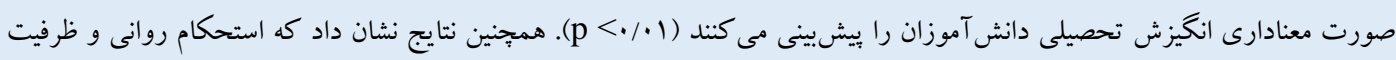

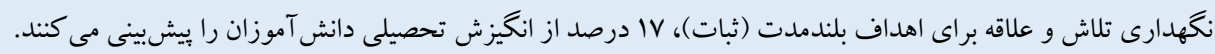
نتيجه كيرى: با توجه به يافتهاى يُزوهش، مشخص شد دانش آموزانى كه داراى اهداف بلندمدتى بوده و برنامه مشخصى براى آينده

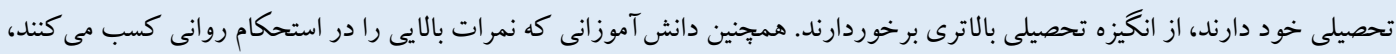

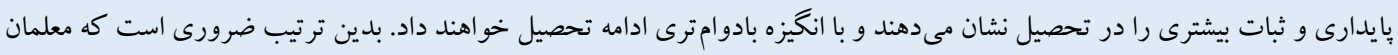
و خانو ادهها با تمركز بيشتر به اين موضوعات در جهت تقويت استحكام روانى و ثبات دانش آموزان، تلاش كنند.
مشخصات مقاله

كليدوازهها:

انخيزش تحصيلى،

استحكام روانى،

تلاش و علاقه،

اهداف بلندمدت،

دانش آموزان

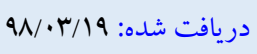

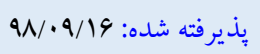
منتشر شده: ب.

* نويسنده مسئول: سيده مريم موسوى، دكتراى روانشناسى سلامت، گروه برستارى، واحد رشت، دانشكاه آزاد اسلامى، رشت، ايران.

راياناه: Mmousavi.msc@gmail.com

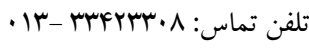


كـه به افراد اين امكان را مي دهند كه در مقابل عوامل فشــار و تنش آور مقاومت كنند (f) (f). در واقع، استحكام روانى مشـخصه بايدار شخصيتى

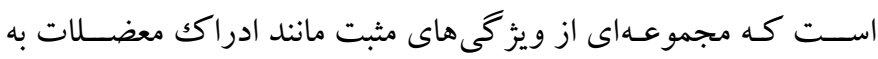

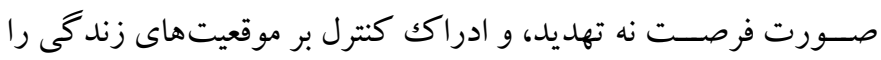

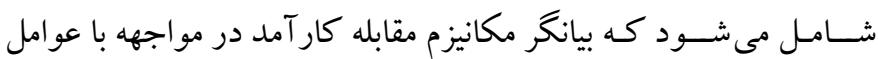
تنش آور و تسهيل موقعيتهايى براى تحول شخصى است (ها). به بيانى

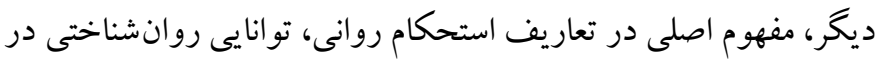

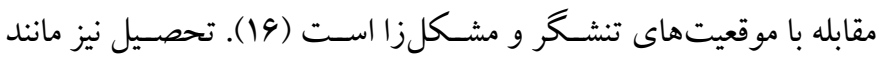

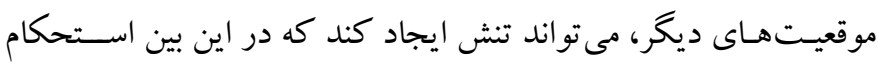
روانى مىتواند نقش مهمى را در زمينه تحصيلى ايفا كند (IV). در همين راسـتا، مطالعات مختلف حاكى از اهميت اسـتحكام روانى در تحصـيل

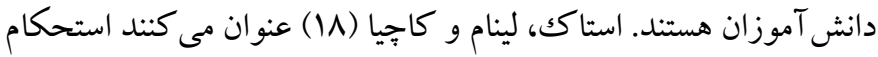

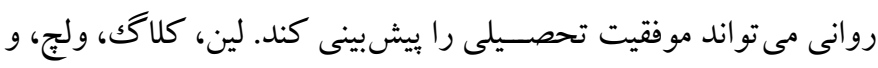

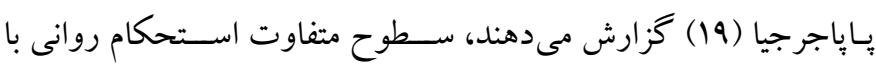

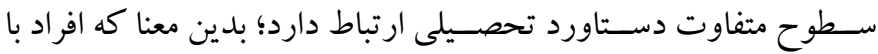
استحكام روانى بيشتر، سطوح بالاتر عملكرد و ويامدهاى تحصيلى راد دارا

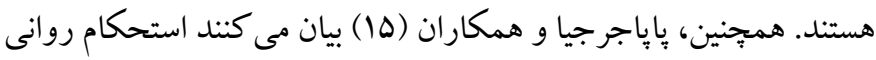

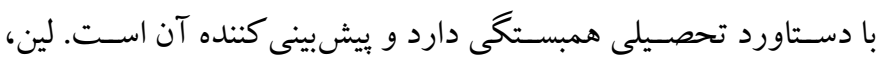

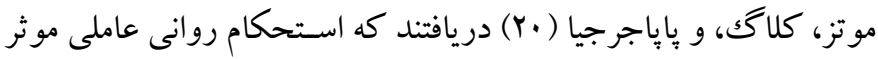

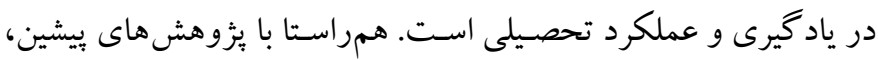

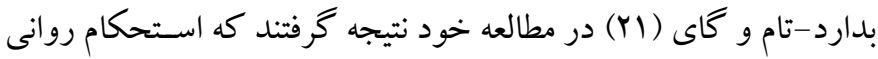
با موفقيت تحصـيلى و تمايل به انجام تكاليف دشــوار، ارتباط دارد؛ به

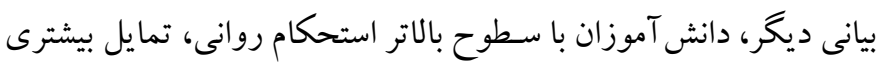

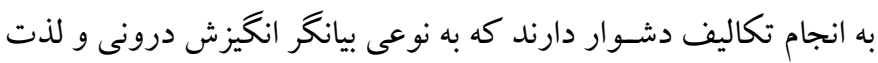

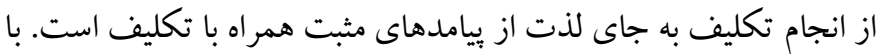
توجه به نبود مطالعات كافى و مشـخص در مورد استحكام روانى و ابعاد

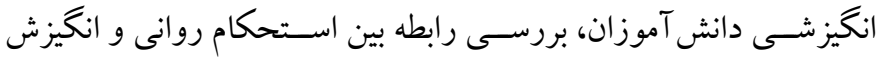
تحصيل دانش آموزان بسيار ضرورى است.

4. Academic stress

5. Academic procrastination

6. Mental toughness
مقلدمه

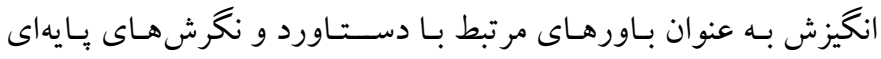

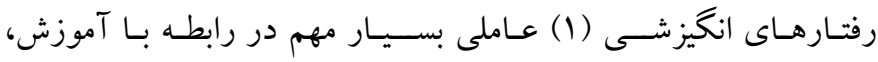

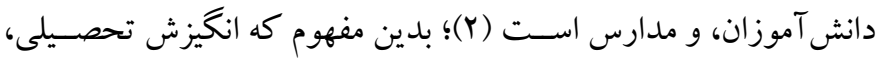
عامل محر كى است كه منجر به مشاركت تحصيلى مى شود (r). در واقع،

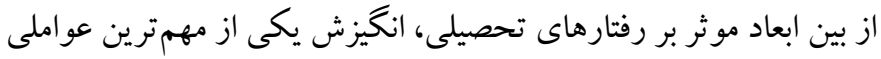

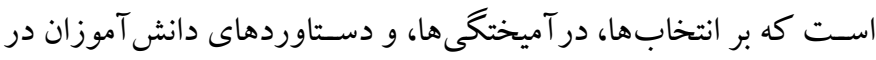

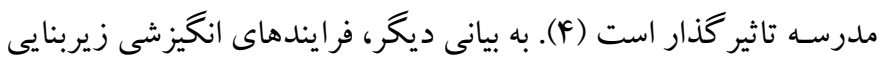

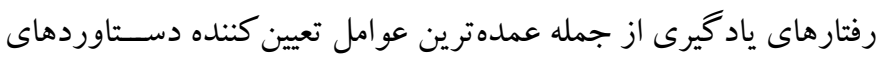

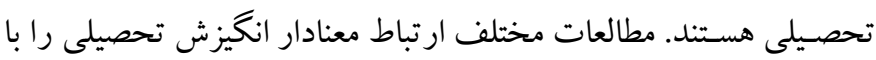
بيـامدهاى مختلف تحصـيلى همجون رتبه تحصـيلى، تلاش و تداوم در

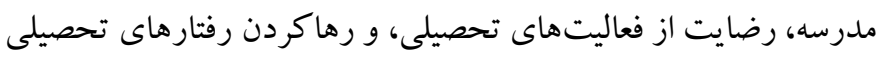

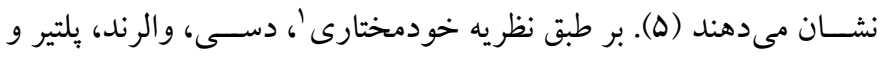

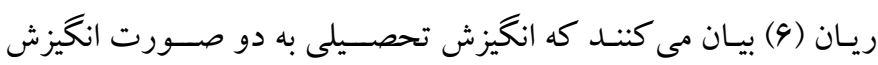

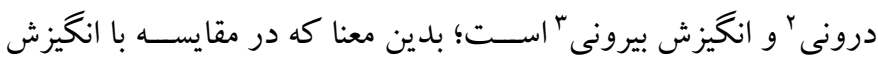

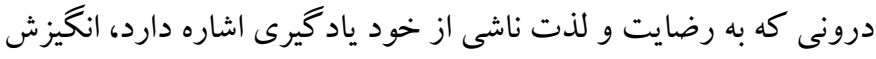

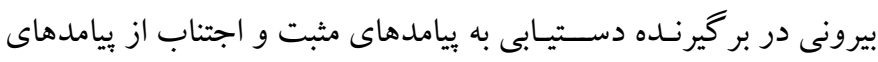

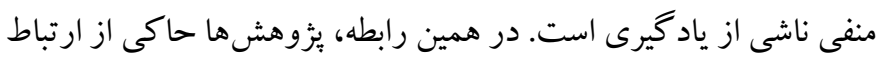

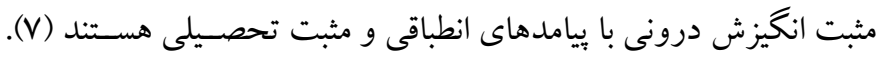

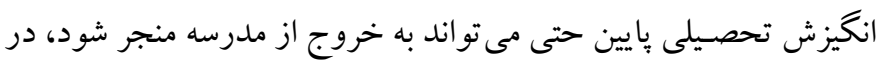

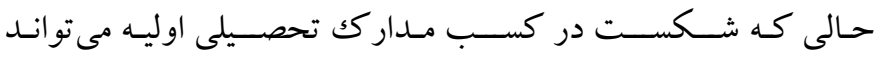

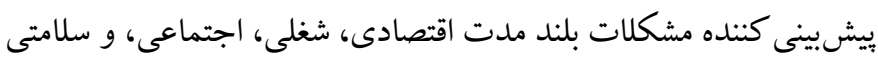

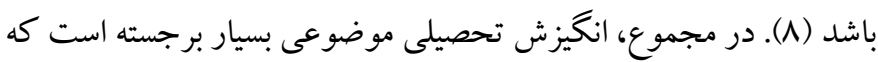

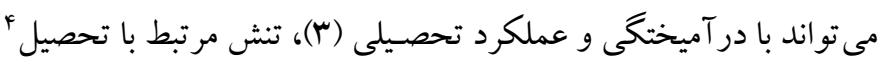

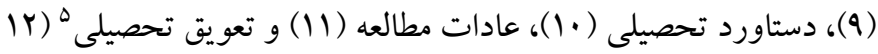
و سا) در ارتباط باشــد كه حاكى از اهميت بديده انكيزش تحصـيلى و استلز ام بررسى آن است. - ماست. اسـتحكام روانى \$ از جمله موضسوعاتى اسـت كه در رابطه با انخيزش

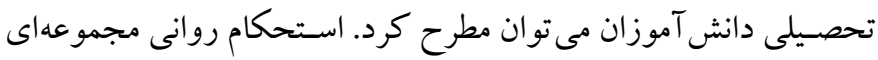

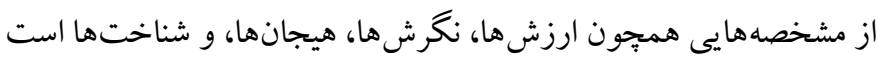

1. Self-determination theory

2. Intrinsic motivation

3. Extrinsic motivation 
رتبه تحصيلى است. بر اين اساس به نظر مىرسد نقش اين سازه در انخيزه تحصيلى و متغيرهاى مرتبط با آن داراى اهميت اساسى است.

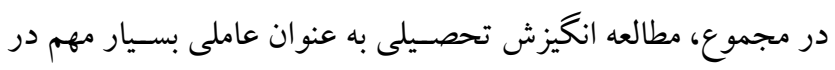
زمينه تحصيلى و بررسى عوامل مرتبط با آن، مسئلهاى بسيار مهم است.

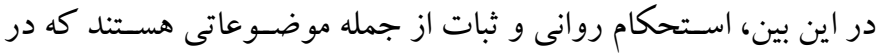

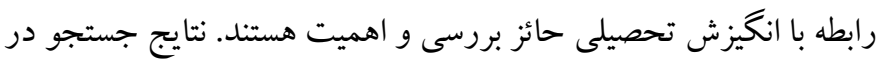

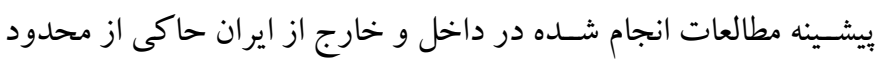
بودن يزوهش هاى انجام شـده در اين حوزه است. بدين ترتيب، هدف از

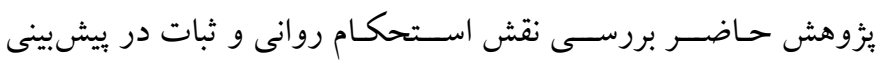
انگيزش تحصيلى دانش آموزان است.

روش

الف) طرح يزوهش و شر كت كنند كان: طرح يزٔوهش حاضر توصيفى

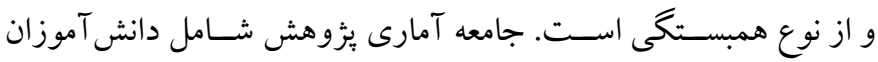

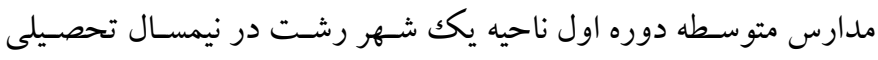

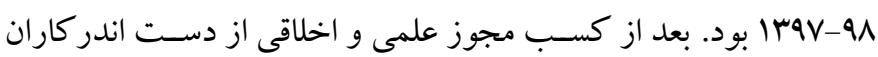

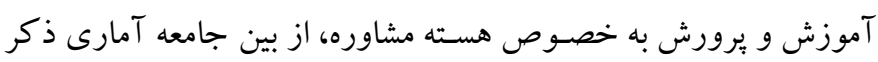

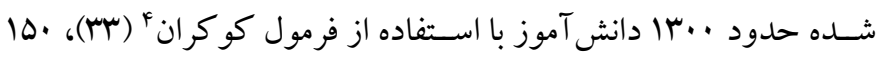
دانش آموز دختر و •ها دانش آموز بِسـر ( ..r دانش آموز در مجموع) مقاطع هفتم، هشتم، و نهم با روش نمونه گيرى در دسترس انتخاب شدند.

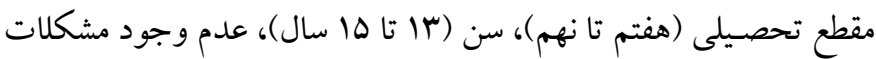
جدى جسـمانى و روانشـناختى قابل مشـاهده، تحت درمان جسـمانى يا روانشـناختى نبودن، و رضسايت شـخصى به عنوان ملاكك ورود در نظر

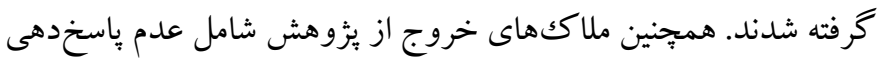
كامل به ابزارها و شانسى جواب دادن به سوالات بود. ب) ب ابزار

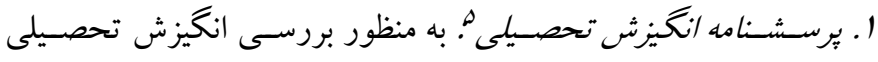

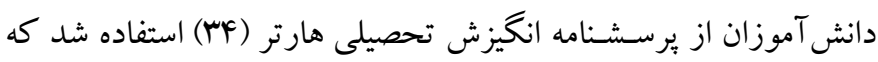

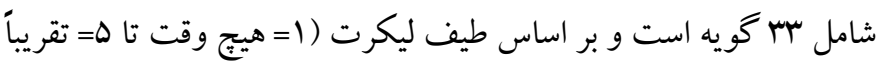
هميشـه) تنظيم شده است. نسخه اصلى اين مقياس توسط هارتر تهيه شده

4. Cochran formula

5. Educational Motivation Scale
علاوه بر استحكام روانى، بايدارى يا ثبات'، مفهوم ديخرى است كه در رابطه با انگيزش تحصيلى مى توان متصور بود. ثبات نقش مهمى رادر برد

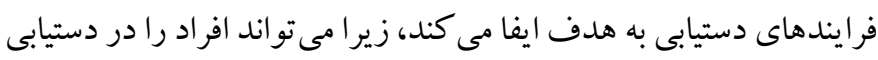
به اهداف معنادار خود در طى مدت زمان طولانى با وجود كامنايافتكى ها، هدا،

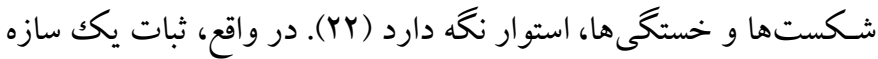
جندبعدى اسـت (rr) كه به عنوان اسـتقامت و اشستياق فرد براى اهداف

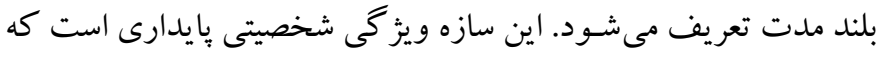

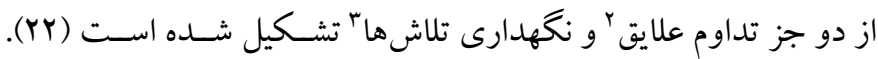

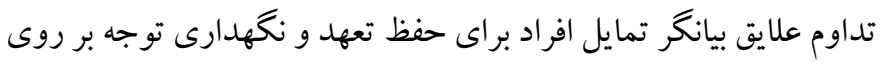

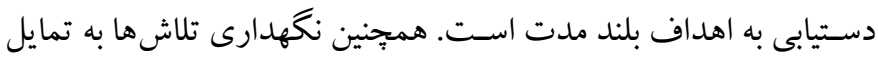

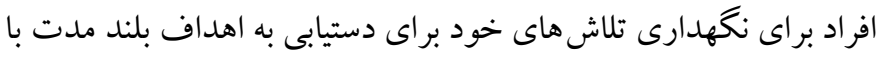

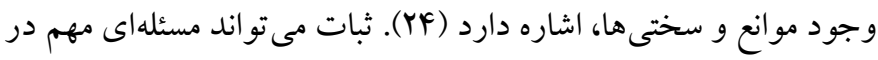

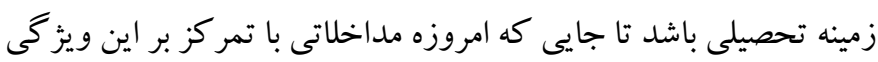

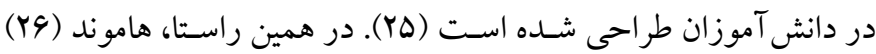

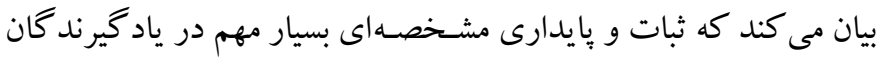

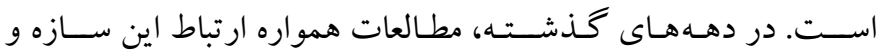
دسـتاوردهاى تحصـيلى را در كود كان، نوجو انان و دانشـجويان نشـان

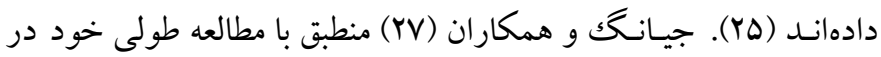

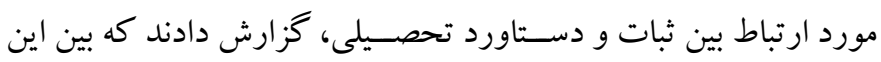
ســازه رابطهاى دو طرفه وجود دارد. ميســون (YN) مطرح مى كند، ثبات بيشبينى كننده عملكرد تحصسيلى اسـت؛ بدين معنا كه ثبات، منبع تغذيه

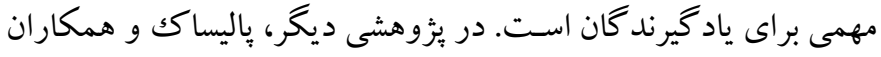

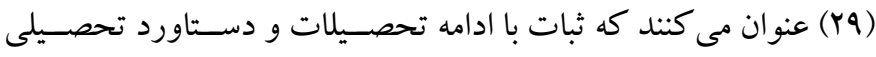

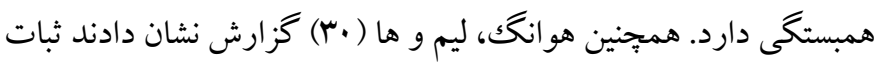

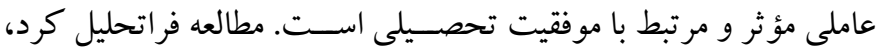

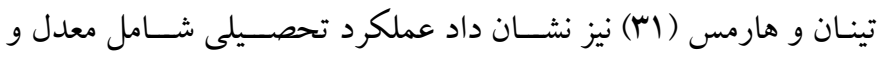

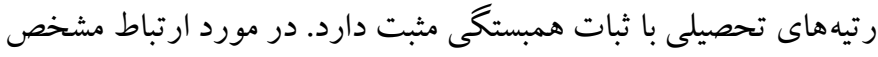

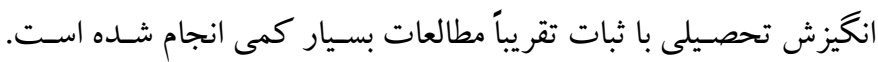

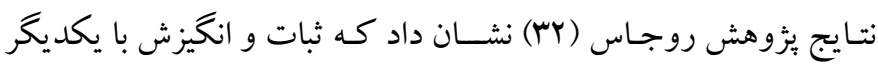

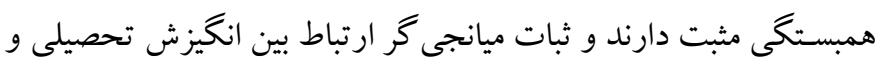

1. Grit

2. Consistency of interests

3. Perseverance of effort 
كرونبـاخ براى اين مقيـاس و خردممقيـاسهـاى اطمينـان، يـايـدارى، و

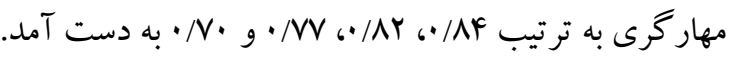

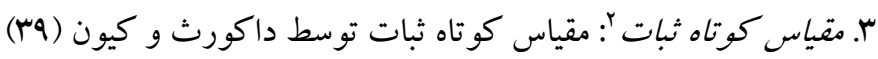

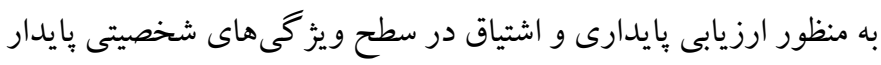
براى اهداف بلندمدت طر احى شـــده اسـت. نســخه كو تاه مقياس ثبات

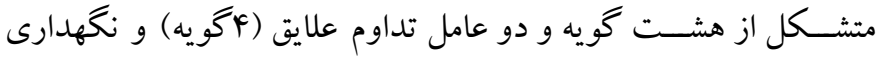
تلاشها (أاكويه) است كه به صورت ليكرت ينج گزينهاى (1=بسيار شبيه

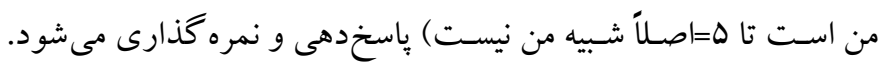

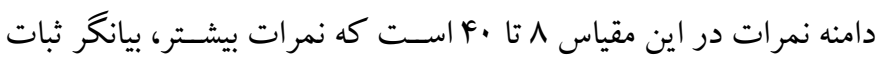
بيشـتر باسـخ دهنده اسـت. داكورث و كيون مشـخصسه هاى روانسـنجى مناسب مقياس كو تاه ثبات را گزارش مىدهند. نتايج تحليل عامل حاكى

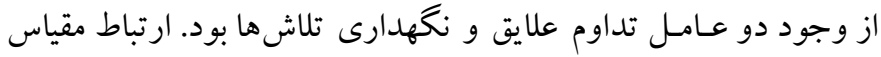

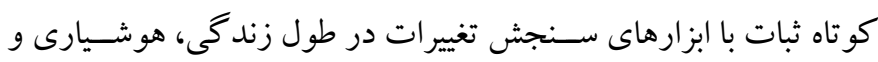

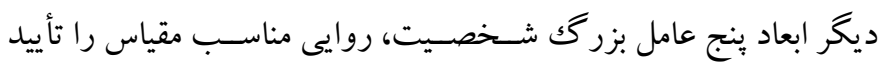

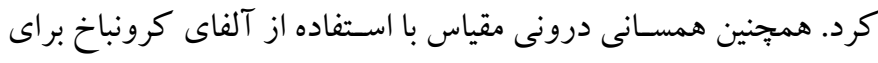

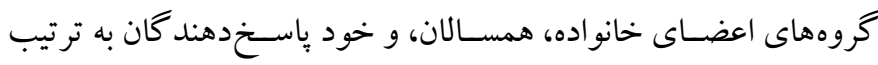

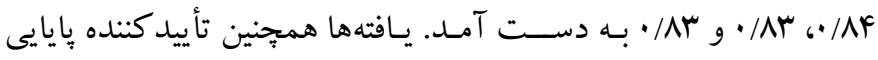

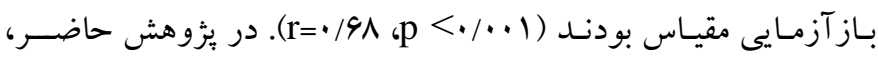

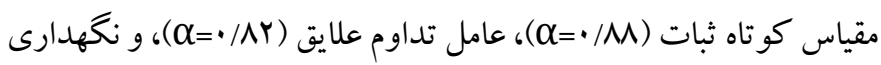
تلاشها (r/N/

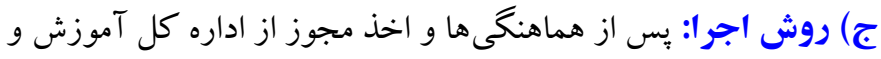

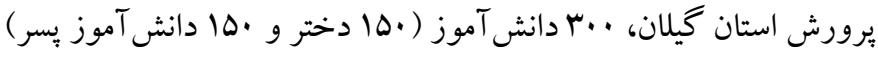

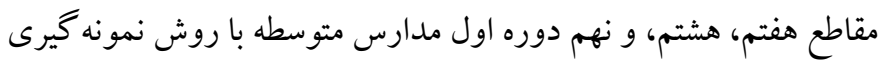

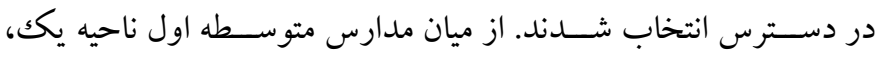

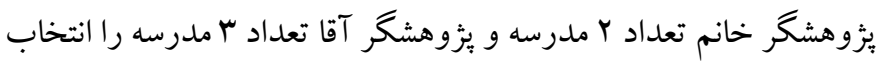

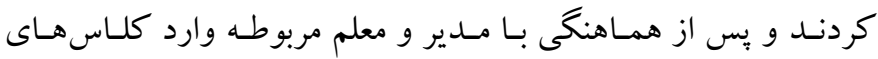

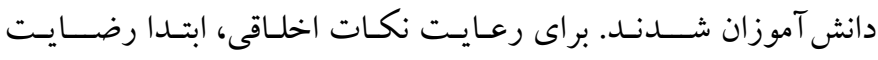

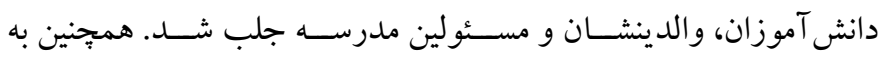

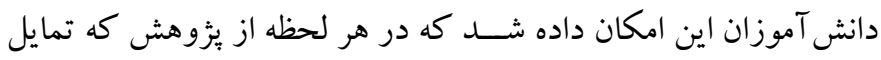
داشتند، انصراف دهند. به منظور اصل رازدارى، به دانش آموزان اطمينان

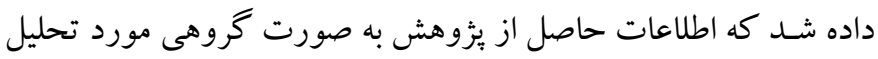

2. Short Grit Scale
است كه انخيزش تحصيلى را به صورت سؤ الهاى دوقطبى مىسنجد كه يكك قطب آن انگيزش بيرونى و قطب ديخر انخيزش درونى را مىسنجد.

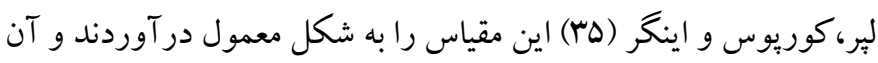

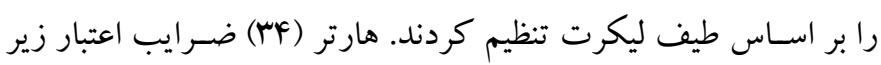

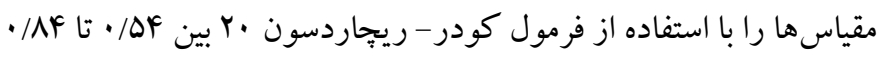

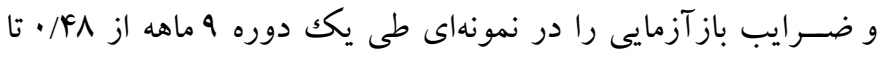

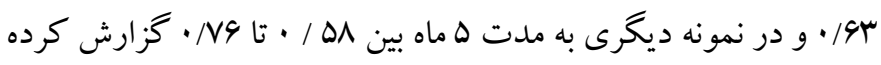
اسـت. بحرانى (q) روايى و اعتبار اين ابزار را در مقطع راهنمايى تأييد

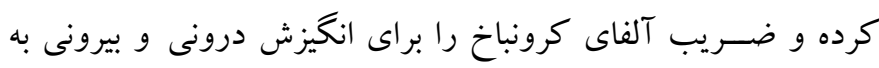

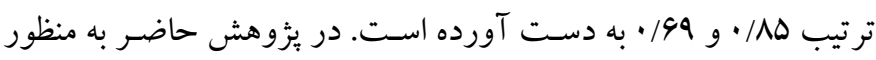

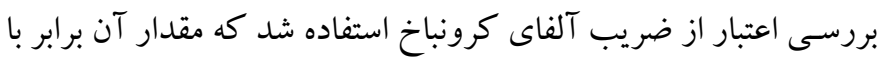

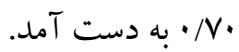
Y. برسشنامه /ستحكام روانى': اين يرسشنامه توسط شرد، گلبى و ونورج

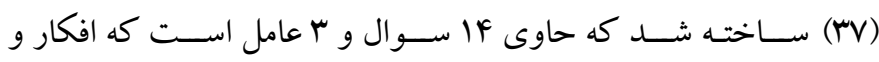

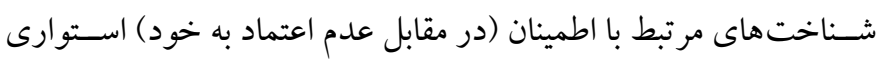

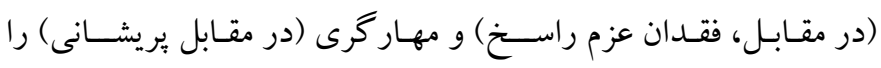

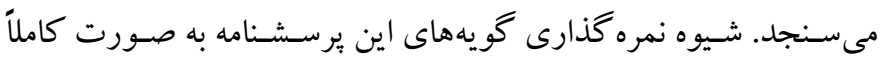

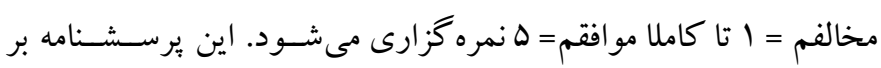

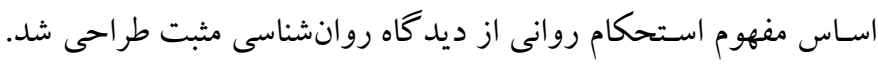

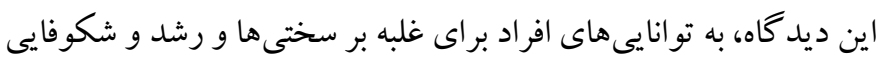

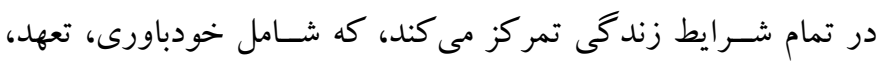

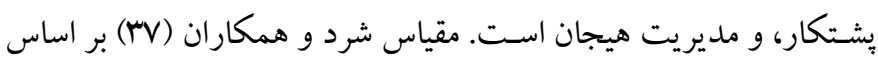

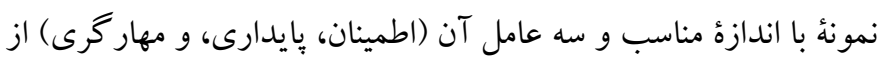

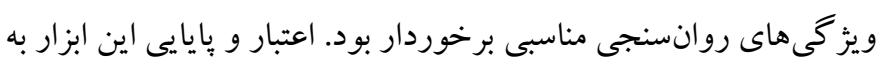

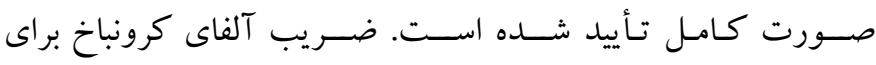

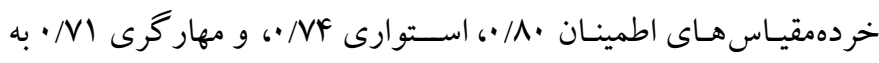

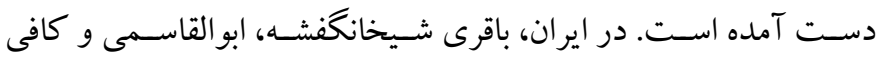

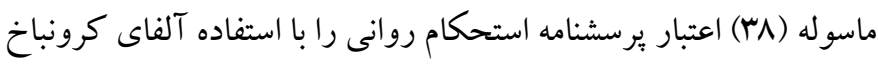

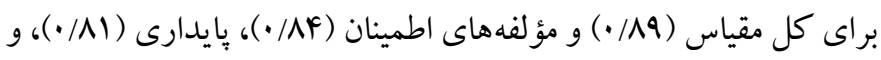

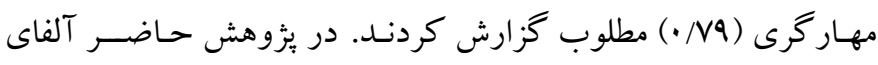

1. Mental toughness scales 
كه قدر مطلق جولكى و كشيدگى متغيرها به ترتيب نبايد از با و · ابيشتر

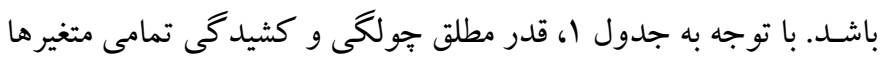

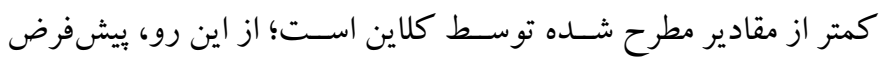

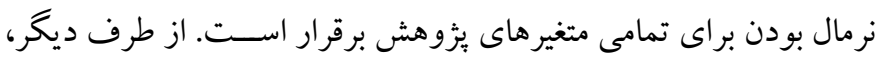

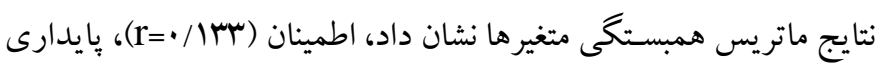

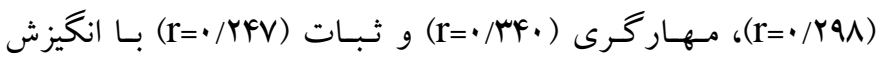
تحصيلى رابطه مثبت معنى دارى در سطح 1 • • دارند.
قرار خواهــ كرفت و اطلـاعات فردىشــان كاملاً محرمانه خواهد ماند. همجنين در اين مطالعه توضيحات شفاهى كاملى در مورد موضوع، روش ترد و اهداف يُزوهش به دانش آموزان، والدين و مسـئولين مدرسـه داده شد.

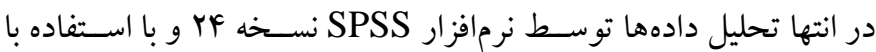

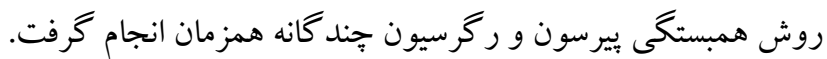

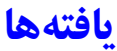

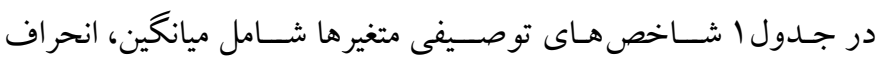

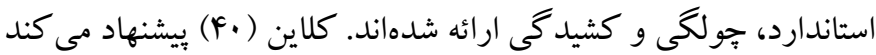

جدول ا: شاخصهاى توصيفى متغيرهاى بزوهش

\begin{tabular}{|c|c|c|c|c|c|c|c|c|c|c|}
\hline 0 & $\varepsilon$ & $r$ & $r$ & 1 & كشيدكى & جولكى & SD & ميانكين & متغير & شماره \\
\hline & & & & 1 & $\cdot / 1 \Delta F$ & $\cdot / 491$ & $r / r q$ & $11 / 91$ & اطمينان & 1 \\
\hline & & & 1 & $. / 944=0$ & $-1 / 49$ & $-\cdot / r q V$ & $r / r$. & $1 . / 90$ & يَايدارى & $r$ \\
\hline & & 1 & $\cdot / 94 \cdot{ }^{* * * *}$ & $\cdot / 019^{* * *}$ & $-\cdot / \Delta 1 Y$ & . TSM & $1 / V^{F}$ & $N / \Delta r$ & كنترل & $r$ \\
\hline & 1 & $\cdot / 490^{* * *}$ & $\cdot /\left.Y Y\right|^{* * * *}$ & $\cdot / r M F^{* * *}$ & $-\cdot / 9 \Lambda$. & $-\cdot / \Delta \Delta \wedge$ & $9 / Y \Lambda$ & YF/DG & ثبات & F \\
\hline 1 & $\cdot / Y F V^{* * *}$ & $\cdot / \mu K \cdot$ * * * & $\cdot / \Upsilon 94$ *** & (سחו/. &.$- / 111$ & $1 / 11$ & $\mid F / A T$ & $9 \Lambda / 11$ & انخيزش تحصيلى & $\Delta$ \\
\hline
\end{tabular}

براى بيش بينى انكيزش تحصيلى از روى استحكام روانى و ثبات،

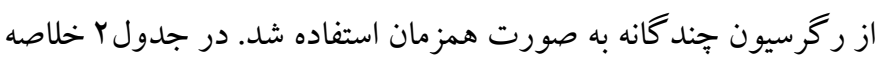
نتايج تحليل رگرسيون گزارش شده است.

جدول r: خلاصه نتايج مدل ييشينى انكيزش تحصيلى از روى استحكام روانى و ثبات

\begin{tabular}{|c|c|c|c|}
\hline خطاى استاندارد بر آورد & تعديل شده R R & واريانس تبيين شده (R2) & همبستغى جند گانه (R) \\
\hline $1 / 1 / 9$ &.$/ 10$ & $\cdot / I V$ & $\cdot|q|$ \\
\hline
\end{tabular}

تحصـيلى را ييشبينى مى كنــد. در جـدول بنتايج تحليل واريانس مدل با توجه به جدول r، ضريب همبستخى جند گانه مؤلفههاى استحكام

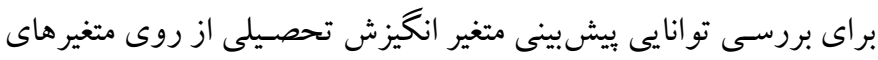

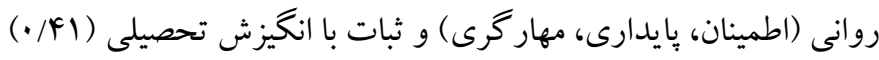
بيش بين گزارش شده است.

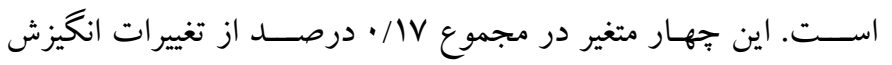

جدول ": نتايج تحليل واريانس ركرسيون جند متغيرى متغير يِشبين از روى متغير ملاكى

\begin{tabular}{|c|c|c|c|c|c|}
\hline سطح معنىدارى & $\mathbf{F}$ & ميانكين مجذورات & درجه آزادى & مجموع مجذورات & مدل \\
\hline \multirow[t]{3}{*}{.$/ \cdot 1$} & $\mid \Delta / \cdot V$ & ₹q११/१1 & f & $19909 / 9 \mathrm{~V}$ & رگرسيون \\
\hline & & $M T / \cdot F$ & ras & १V९DN/9. & باقيمانده \\
\hline & & & ५৭৭ & IIVGIN/YA & كل \\
\hline
\end{tabular}


توجـه به آنكه شــاخص ســطح تحمل ' براى تمامى متغيرها زير يكك به

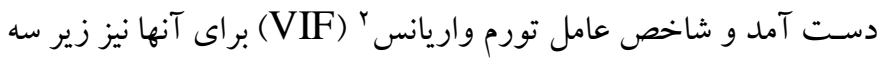

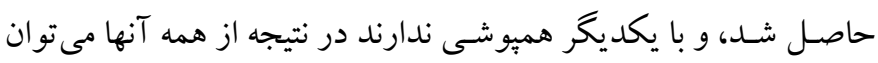

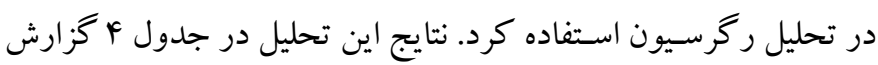

شده است.

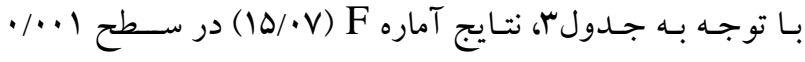

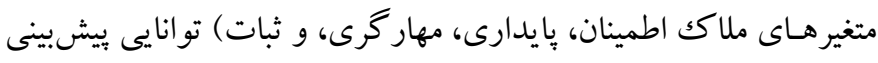

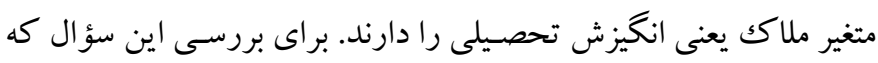

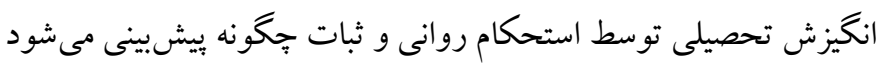

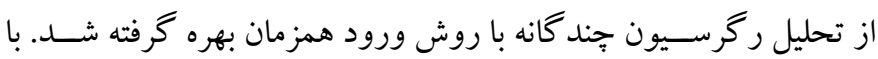

جدول ع: ضرايب ركر سيون استاندارد نشده و استاندارد شده مدل بيشيينى انكيزش تحصيلى

\begin{tabular}{|c|c|c|c|c|c|c|c|}
\hline \multirow[b]{2}{*}{ VIF } & \multirow[b]{2}{*}{ سطح تحمل } & \multirow[b]{2}{*}{$\mathbf{p}$} & \multicolumn{2}{|c|}{ ضرايب استاندارد شده } & \multicolumn{2}{|c|}{ ضرايب استاندارد نشده } & \multirow{2}{*}{ مدل } \\
\hline & & & $\mathbf{T}$ & Beta & خطاى استاندارد بر آورد & B & \\
\hline- & - & $\cdot / \cdot 1$ & $\Delta / \wedge$. & - & $\Lambda / 9 \mathrm{~V}$ & $\Delta \cdot / r Y$ & عدد ثابت a ع \\
\hline $1 / \mathrm{V} \Lambda$ & - /DGY &.$/ .1 \mathrm{~V}$ & $r / f 1$ & $\cdot / \mathrm{IV}$ & $\cdot / 4 \mid$ & $\cdot / 99$ & اطمينان \\
\hline$r / 10$ & ./FGT & 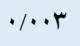 & $Y / 9 V$ & 每 & $\cdot / v$ & $r / \cdot \Lambda$ & 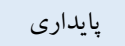 \\
\hline $1 / 19$ & . /OrG & 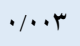 & Y/৭९ & $\cdot / Y 1$ & $\cdot / \Lambda Y$ & r/Fr & 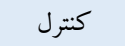 \\
\hline $1 / 10$ & . /AGY &.$/ .1$ & $r / r l$ & $\cdot / 1 \Lambda$ & $\cdot / \wedge \Lambda$ & $\cdot / \Delta \Lambda$ & ثبات \\
\hline
\end{tabular}

بايدارى، مهار گرى) با انگيزش تحصيلى دانش آموزان همبستگى مثبت و

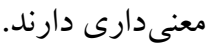
اسـتحكام روانى در افراد بـه عوان يـك مكـانيزم مقابله كار آمد در

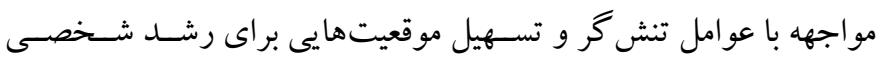

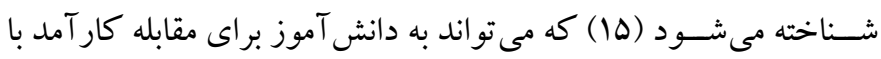

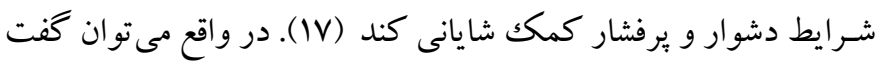

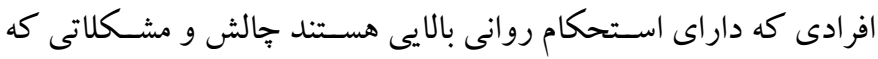

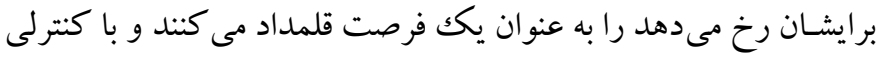

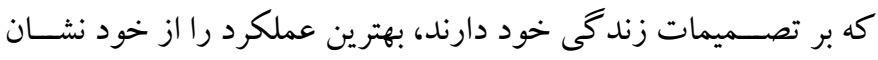

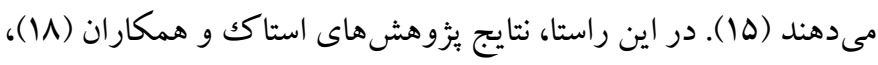

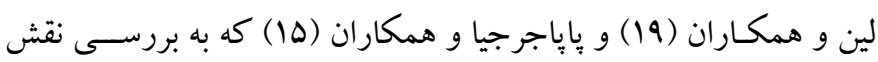

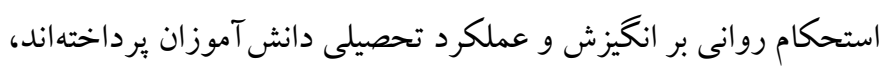

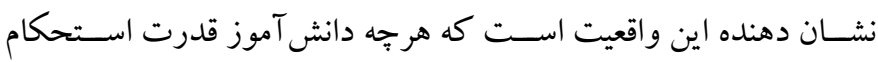

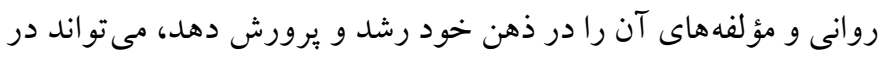

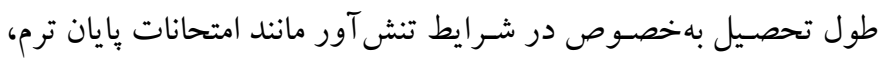

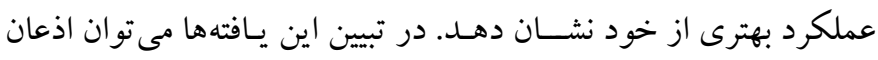

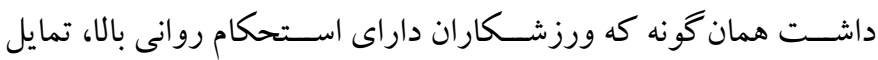

2. Variance inflation factor

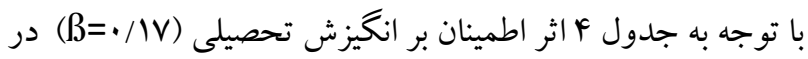

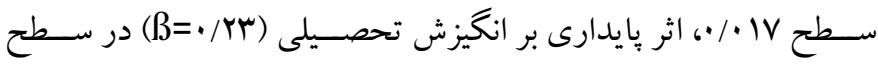

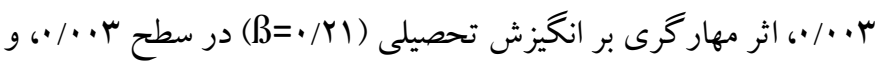

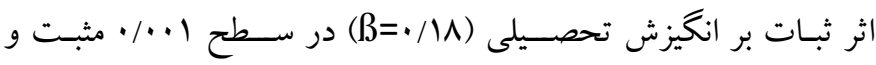
معنى دار اســت. در واقع، اســحكام روانى و ثبات با انكيزش تحصـيلى همبستك مثبت دارند كه نشانكر آن است كه هر جه قدر ميز ان استحكام روانى و ثبات در دانش آموزان بالا باشــد، ميزان انكخزش تحصـيلى فرد بالاتر خواهد بود و برعكس.

\section{بحث و نتيجه تيرى}

يثزوهش حاضـر به منظور بررسـى ارتباط انكيزش تحصـيلى، اسـتحكام روانى، و ظرفيـت نكهـدارى تلاش و علاقه براى اهداف بلندمدت (ثبات) در دانش آموزان يسر و دختر مقاطع هفتم، هشتم، و نهم دوره اول مدارس متوسـطه ناحيه يكك شـهر رشـت در نيمسـال تحصسيلى

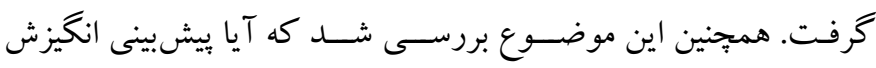
تحصـيلى از طريق بررسـى اسـتحكام روانى و ظرفيت نكهدارى تلاش و علـاقه براى اهداف بلندمدت در دانش آموزان امكانيذير اسـتـ يا خير. نتـايج به دســت آمده نشــان داد مؤلفههاى اســتحكام روانى (اطمينان، 
مانند استحكام روانى و ثبات نيازمند توجه بيشـترى از سوى بثزوهشكران

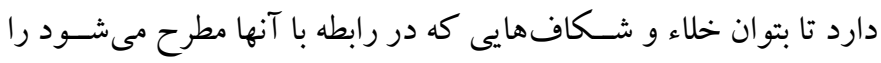

$$
\text { بهتو ان يوشش داد. }
$$

ئزوهش حاضـر محدوديتهايى را به همر اه داشـته اسـت كه در به

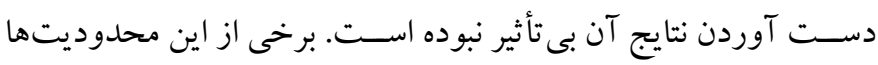

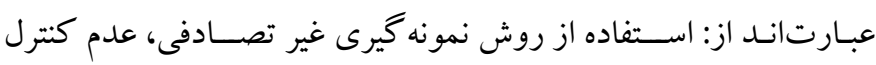
متغيرهاى واسطهاى مؤثر بر انگيزش تحصيلى دانش آموزان، محدود بودن

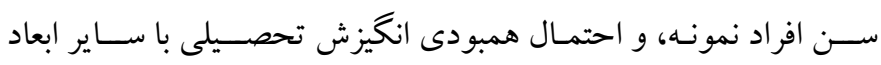

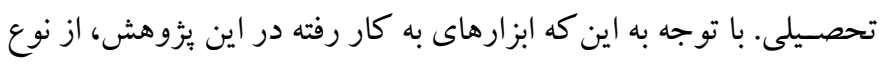

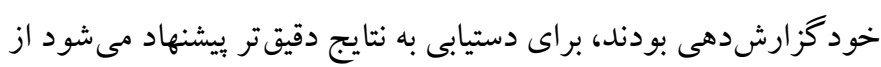
مشـاهده و مصاحبه بالينى نيز استفاده شود. در عين حال بر اساس نتايج

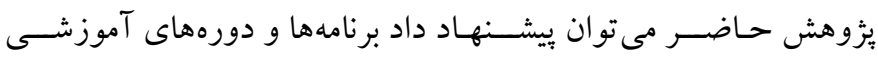

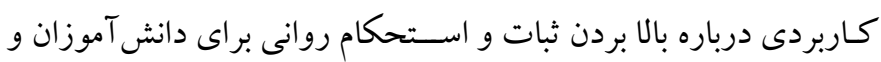

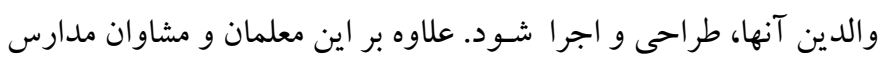

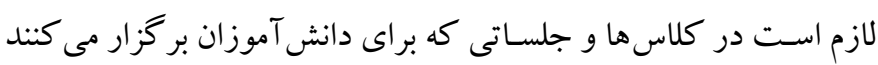

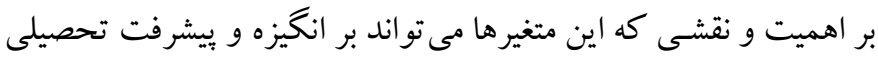
دانش آموزان داشته باشد، تأكيد كنند.

تشكر و قدردانى: اين مطالعه به صورت مستقل اجر اشده و حاصل بايانامه

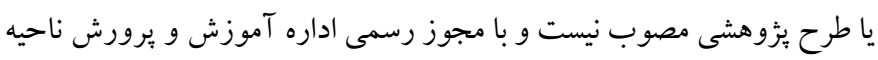

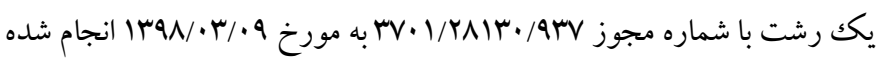

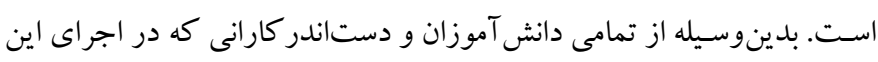

$$
\text { تيزوهش مشار كت داشتند تشكر و قدردانى مى شود. }
$$

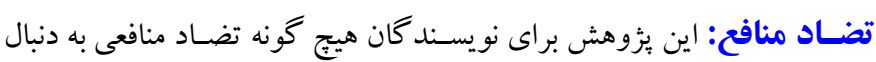
نداشته است و نتايج آن به صورت شفاف بيان شده است.
بيشترى به انجام تمرين هاى برفشار و سنگين را دارند، دانش آموزانى هم

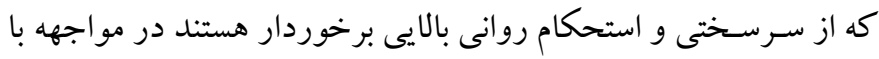

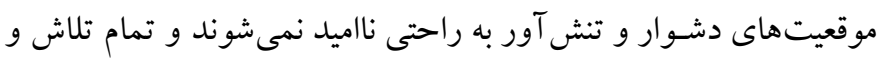

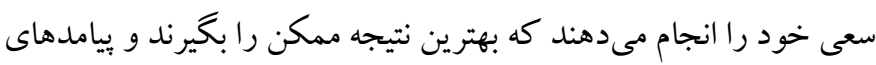
مثبتى را كه همراه با تكليف است تجربه كنند (Y) (Y). از سوى ديخر، نتايج يثزوهش حاضر نشان داد ظرفيت نخهدارى تلاش و علاقه براى اهداف بلندمدت (ثبات) با انخيزش تحصسيلى دانش آموزان

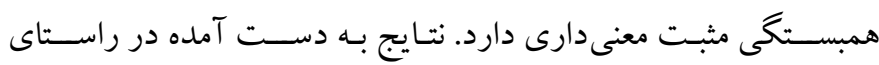

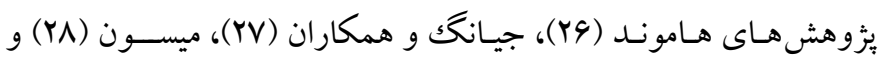

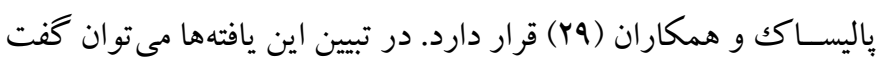
دانش آموزانى كه در طول تحصيل خود برنامهريزى درستى براى اهداف

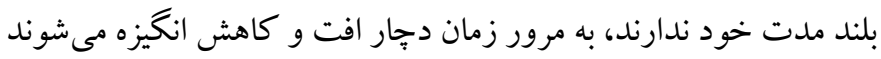
و انگيزه درس خواندن و تحصيل در آنها به طور جشمخيرى كاهش بـ بيدا

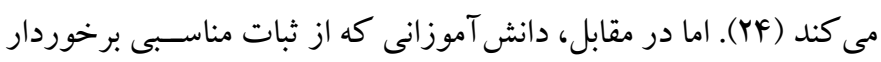

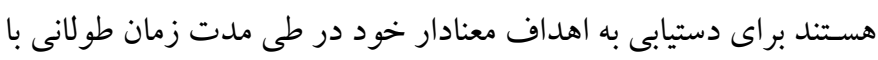

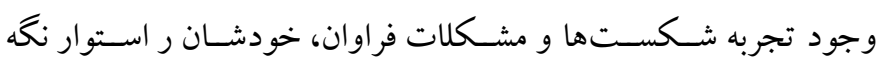

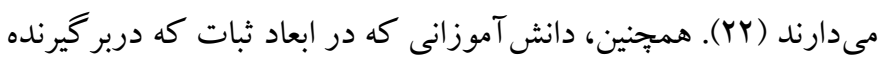

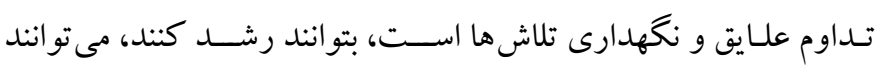
بهترين انتخاب را در زمينه تحصيلى داشته باشند و بدون وقفه و احساس

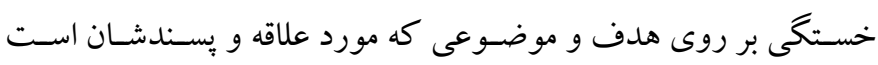

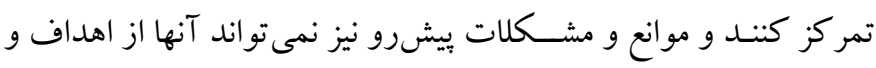

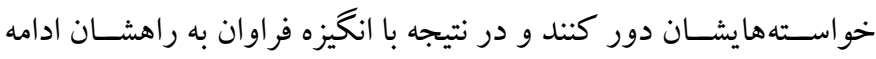

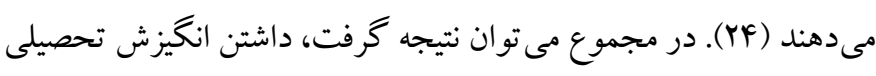

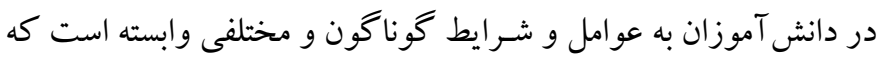

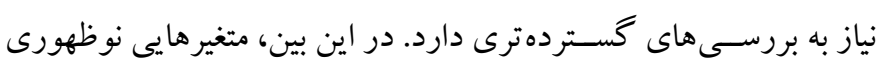




\section{References}

1. Wigfield A, Eccles JS, Schiefele U, Roeser RW, DavisKean P. Development of achievement motivation. In: Damon W, Lerner RM, Eisenberg N, editors. Handbook of child psychology, vol. 3: social, emotional, and personality development. 6th edition. Hoboken, N.J: Wiley; 2006, pp: 933-1002. [Link]

2. Lazarides R, Viljaranta J, Aunola K, Pesu L, Nurmi JE. The role of parental expectations and students' motivational profiles for educational aspirations. Learn Individ Differ. 2016; 51: 29-36. [Link]

3. Clark MH, Middleton SC, Nguyen D, Zwick LK. Mediating relationships between academic motivation, academic integration and academic performance. Learn Individ Differ. 2014; 33: 30-38. [Link]

4. Jiang Y, Rosenzweig EQ, Gaspard H. An expectancyvalue-cost approach in predicting adolescent students' academic motivation and achievement. Contemp Educ Psychol. 2018; 54: 139-152. [Link]

5. Vecchione M, Alessandri G, Marsicano G. Academic motivation predicts educational attainment: does gender make a difference? Learn Individ Differ. 2014; 32: 124-131. [Link]

6. Deci EL, Vallerand RJ, Pelletier LG, Ryan RM. Motivation and education: The self-determination perspective. Educ Psychol. 1991; 26(3-4): 325-346. [Link]

7. Vallerand RJ, Pelletier LG, Koestner R. Reflections on self-determination theory. Can Psychol. 2008; 49(3): 257-262. [Link]

8. Cham H, Hughes JN, West SG, Im MH. Effect of retention in elementary grades on grade 9 motivation for educational attainment. J Sch Psychol. 2015; 53(1): 7-24. [Link]

9. Liu Y. The longitudinal relationship between Chinese high school students' academic stress and academic motivation. Learn Individ Differ. 2015; 38: 123-126. [Link]

10. Gupta PK, Rashmi M. Impact of academic motivation on academic achievement: A study on high schools students. European Journal of Education Studies. 2016; 2(10): 43-51. [Link]

11. Entwistle NJ, Thompson J, Wilson JD. Motivation and study habits. High Educ. 1974; 3(4): 379-396. [Link]

12. Klassen RM, Kuzucu E. Academic procrastination and motivation of adolescents in Turkey. Educ Psychol. 2009; 29(1): 69-81. [Link]
13. Wu F, Fan W. Academic procrastination in linking motivation and achievement-related behaviors: a perspective of expectancy-value theory. Educ Psychol. 2017; 37(6): 695-711. [Link]

14. Manley H, Jarukasemthawee S, Pisitsungkagarn K. The effect of narcissistic admiration and rivalry on mental toughness. Pers Individ Dif. 2019; 148: 1-6. [Link]

15. Papageorgiou KA, Malanchini M, Denovan A, Clough PJ, Shakeshaft N, Schofield K, et al. Longitudinal associations between narcissism, mental toughness and school achievement. Pers Individ Dif. 2018; 131: 105-110. [Link]

16. Gucciardi DF. Mental toughness: progress and prospects. Curr Opin Psychol. 2017; 16: 17-23. [Link]

17. Clair-Thompson H, Bugler M, Robinson J, Clough P, McGeown SP, Perry J. Mental toughness in education: exploring relationships with attainment, attendance, behavior and peer relationships. Educ Psychol. 2015; 35(7): 886-907. [Link]

18. Stock R, Lynam S, Cachia M. Academic success: the role of mental toughness in predicting and creating success. High Educ Pedagog. 2018; 3(1): 429-433. [Link]

19. Lin Y, Clough PJ, Welch J, Papageorgiou KA. Individual differences in mental toughness associate with academic performance and income. Pers Individ Dif. 2017; 113: 178-183. [Link]

20. Lin Y, Mutz J, Clough PJ, Papageorgiou KA. Mental toughness and individual differences in learning, educational and work performance, psychological well-being, and personality: a systematic review. Front Psychol. 2017; 8: 1345. [Link]

21. Bédard-Thom C, Guay F. Mental toughness among high school students: a test of its multidimensionality and nomological validity with academic achievement and preference for difficult tasks. Soc Psychol Educ. 2018; 21(4): 827-848. [Link]

22. Duckworth AL, Peterson C, Matthews MD, Kelly DR. Grit: perseverance and passion for long-term goals. J Pers Soc Psychol. 2007; 92(6): 1087-1101. [Link]

23. Cormier DL, Dunn JGH, Dun JC. Examining the domain specificity of grit. Pers Individ Dif. 2019; 139: 349-354. [Link]

24. Duckworth A, Gross JJ. Self-control and grit: related but separable determinants of success. Curr Dir Psychol Sci. 2014; 23(5): 319-325. [Link]

25. Clark KN, Malecki CK. Academic grit scale: psychometric properties and associations with 
achievement and life satisfaction. J Sch Psychol. 2019; 72: 49-66. [Link]

26. Hammond DA. Grit: an important characteristic in learners. Curr Pharm Teach Learn. 2017; 9(1): 1-3. [Link]

27. Jiang W, Xiao Z, Liu Y, Guo K, Jiang J, Du X. Reciprocal relations between grit and academic achievement: a longitudinal study. Learn Individ Differ. 2019; 71: 13-22. [Link]

28. Mason HD. Grit and academic performance among first-year university students: a brief report. J Psychol Afr. 2018; 28(1): 66-68. [Link]

29. Palisoc AJL, Matsumoto RR, Ho J, Perry PJ, Tang TT, Ip EJ. Relationship between grit with academic performance and attainment of postgraduate training in pharmacy students. Am J Pharm Educ. 2017; 81(4): 67. [Link]

30. Hwang MH, Lim HJ, Ha HS. Effects of grit on the academic success of adult female students at Korean open university. Psychol Rep. 2018; 121(4): 705-725. [Link]

31. Credé M, Tynan MC, Harms PD. Much ado about grit: a meta-analytic synthesis of the grit literature. J Pers Soc Psychol. 2017; 113(3): 492-511. [Link]

32. Rojas JP. The relationships among creativity, grit, academic motivation, and academic success in college students. [PhD Theses]. [Kentucky, United States]: Department of Educational and Counseling Psych, University of Kentucky; 2015, pp: 1-132. [Link]
33. Charan J, Biswas T. How to calculate sample size for different study designs in medical research? Indian J Psychol Med. 2013; 35(2): 121-126. [Link]

34. Harter S. A new self-report scale of intrinsic versus extrinsic orientation in the classroom: Motivational and informational components. Dev Psychol. 1981; 17(3): 300-312. [Link]

35. Lepper MR, Corpus JH, Iyengar SS. Intrinsic and extrinsic motivational orientations in the classroom: age differences and academic correlates. J Educ Psychol. 2005; 97(2): 184-196. [Link]

36. Bahrani M. The study of validity and reliability of Harter's scale of educational motivation. Journal of Psychological Studies. 2009; 5(1): 51-72. [Persian]. [Link]

37. Sheard M, Golby J, van Wersch A. Progress toward construct validation of the sports mental toughness questionnaire (SMTQ). Eur J Psychol Assess. 2009; 25(3): 186-193. [Link]

38. Bagheri Sheykhangafshe F, Abolghasemi A, Kafi Masouleh SM. Comparison dark triad traits of personality, cognitive decision-making and mental toughness in natural, supplement and steroid bodybuilders. Sport Psychology Studies. 2020; 8(29): 19-38. [Persian]. [Link]

39. Duckworth AL, Quinn PD. Development and validation of the short grit scale (grit-s). J Pers Assess. 2009; 91(2): 166-174. [Link]

40. Kline RB. Principles and practice of structural equation modeling. Fourth Edition. New York: The Guilford Press; 2011. [Link] 